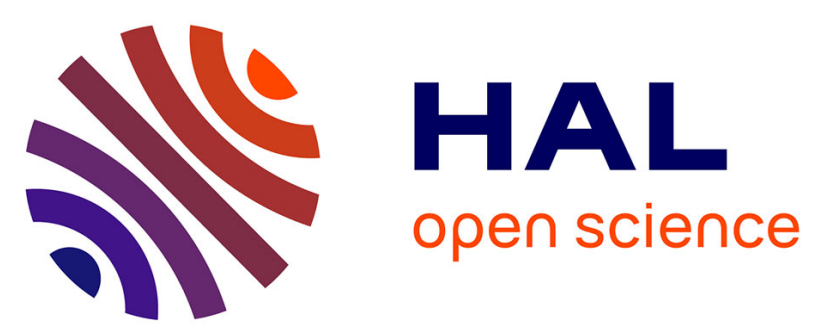

\title{
Effects of fungal decay on elasticity and damping of small-diameter silver fir logs assessed by the transverse vibration resonant method
}

Jean Baptiste Barré, Franck Bourrier, Loïc Brancheriau, Freddy Rey, David Bertrand

\section{To cite this version:}

Jean Baptiste Barré, Franck Bourrier, Loïc Brancheriau, Freddy Rey, David Bertrand. Effects of fungal decay on elasticity and damping of small-diameter silver fir logs assessed by the transverse vibration resonant method. Wood Science and Technology, 2018, 52 (2), pp.403-420. 10.1007/s00226-017-09612. hal-01824007

\section{HAL Id: hal-01824007 https://hal.science/hal-01824007}

Submitted on 5 Oct 2018

HAL is a multi-disciplinary open access archive for the deposit and dissemination of scientific research documents, whether they are published or not. The documents may come from teaching and research institutions in France or abroad, or from public or private research centers.
L'archive ouverte pluridisciplinaire HAL, est destinée au dépôt et à la diffusion de documents scientifiques de niveau recherche, publiés ou non, émanant des établissements d'enseignement et de recherche français ou étrangers, des laboratoires publics ou privés. 


\title{
Effects of fungal decay on elasticity and damping of small-diameter silver fir logs assessed by the transverse vibration resonant method
}

\author{
Jean Baptiste Barré ${ }^{1}$ - Franck Bourrier ${ }^{1}$. \\ Loïc Brancheriau ${ }^{2}$ - David Bertrand ${ }^{3}$. \\ Freddy $\operatorname{Rey}^{1}$
}

\begin{abstract}
A number of studies have shown the ability of the vibration resonant method (VRM) to measure the modulus of elasticity (MOE) and the damping ratio $(\xi)$ of calibrated wooden samples of various dimensions. This method based on free transverse vibrations was also studied to assess the decay extent in small stakes. Nevertheless, a need for investigations was identified in order to apply the method to decayed logs. Both decay and geometrical singularities brought heterogeneity not taken into account by the VRM. The aim of this study was to examine the effects of fungal decay on these two mechanical properties of small-diameter silver fir logs using the VRM. Fifty-five small-diameter logs were monitored over a decay process taking place in a greenhouse located near Grenoble (France). The MOE and $\xi$ were measured in intact and decayed states. The results showed the reliability of the measurements of both properties. $\xi$ was found to be independent of moisture content for wood above the fibre saturation point. The results validated the loss in MOE and the gain in $\xi$ due to fungal activity. Thus, indicators based on the MOE and $\xi$ were proposed and compared to quantify the decay extent. Indicators calculated from the first mode of vibration appeared to be relevant for that purpose. Future work is needed to validate indicators on structural size logs and to compare this quantitative assessment to those obtained by the standard EN 152 that currently serves as a benchmark.
\end{abstract}

Jean Baptiste Barré

jean-baptiste.barre@irstea.fr

1 Irstea, UR EMGR, Université Grenoble Alpes, 2 rue de la Papeterie-BP 76, 38402 St-Martin-d'Hères, France

2 UR BioWooEB UMR AMAP, CIRAD, 34398 Montpellier Cedex 5, France

3 INSA Lyon (National Institute of Applied Sciences of Lyon), Université de Lyon, 20, Avenue Albert Einstein, Villeurbanne Cedex, France 


\section{Introduction}

Natural hazards such as erosion or small landslides may be mitigated by ecological engineering structures built from a wooden logs framework. These timber structures are mostly made of local softwoods such as, in the French Alps, larch, Douglas fir, pine or silver fir. Built in ground contact without any wood preservatives, they undergo fungal attacks since their construction starts. Fungi are well known to have dramatic effects on wood mechanical properties (Curling et al. 2002) depending on, inter alia, wood species, wood moisture content and temperature (Zabel and Morrell 1992). The two last parameters fluctuate significantly geographically and in time (Brischke and Rapp 2008). As a consequence, practitioners meet difficulties in quantifying the decay extent of logs. The standard EN 252 (CEN 2014) serves as benchmark to assess the decay extent of samples decayed in the field. It is based on qualitative method that is hardly repeatable from one experiment to another. Other standards such as EN 15083 (CEN 2006) proposed quantitative methods based on mass loss between intact and decayed states. However, the methods are applicable in controlled conditions and hardly transferable to field applications. Moreover, the mass loss due to decay is slower than the loss in mechanical properties (Curling et al. 2002). Thus, the assessment of the decay extent by means of the measurement of mechanical properties variations is more relevant in the context of ecological engineering structures, especially for the early stages of decay. For that purpose, practitioners can use non-destructive methods which have been developed to appraise structures (Cruz et al. 2015; Tannert et al. 2013; Riggio et al. 2013). However, few of them are suited to the constraints of these outdoor timber structures. The non-destructive method has to be battery powered, little influenced by moisture content (MC) of wood, especially when it is above the fibre saturation point (FSP) and, finally, applicable to little decayed logs as well as severely decayed logs including some cracks. Researches have studied methods suited to these constraints as time domain reflectometry water content measurements or methods based on species composition and population structures of basidiomycetes in wood (Previati et al. 2012; Noetzli et al. 2008). Others developed methods allowing to overcome them as methods based on near infrared spectroscopy (Barré et al. 2017; Sandak et al. 2015). However, none of them assesses impact of decay on the mechanical properties in a cost-effective way. This brings to light the vibration resonant method (VRM), another common non-destructive method.

The vibration resonant method is currently used for mechanical grading of intact (non-attacked) timber beams (Stapel and van de Kuilen 2013). The method is fast and non-destructive. It consists of recording the displacement of a freely supported beam subjected to longitudinal or transversal vibrations. From this measurement, the Euler-Bernoulli or Timoshenko beam theories allow to calculate the modulus of elasticity (MOE). The VRM has initially been elaborated to calculate the MOE for beams of regular cross section and homogeneous material. However, studies have shown its relevancy by comparison with static bending techniques for timber beam including geometric or material singularities. Wang et al. (2002) found a strong correlation $\left(R^{2}=0.85\right.$ for Jack pine and 0.95 for red pine) between the MOE 
obtained by transverse vibration $\left(E_{\mathrm{tv}}\right)$ and by static bending technique $\left(\mathrm{MOE}_{s}\right)$ for $\operatorname{logs}(3.7 \mathrm{~m}$ in length and MC above FSP), i.e. a piece of wood which has not been shaped by hewing or sawing. The logs diameter was between 11.9 and $27.9 \mathrm{~cm}$. This result has been confirmed by Green et al. (2006) who obtained high correlation $\left(R^{2}=0.88\right)$ for perfectly round large timber beams (diameter of $22.8 \mathrm{~cm}$, length of $500 \mathrm{~cm}$ and MC of $15.5 \%$ ). Finally, for wood above its fibre saturation point (FSP) and compared to other methods based on sound or ultrasound propagation, the VRM measures the MOE without being influenced by the moisture content as the MOE remains constant above the FSP (Machek et al. 2001; Barrett and Hong 2009).

Furthermore, the VRM has been studied to investigate influence of decay on bending property. Grinda and Göller (2005) and Alfredsen et al. (2006) confirmed the VRM is a relevant method to quantify decay in wood. Nevertheless, these studies consider small rectangular stakes with a maximum of $500 \mathrm{~mm}$ in length and $50 \mathrm{~mm}$ in height. The small sample size limits the number of defects, which are naturally present in wood and influence the measure of the MOE. They differ importantly from the beams used in ecological engineering timber structures (logs of diameter from 10 to $30 \mathrm{~cm}$ ). Moreover, regarding decayed wood and the VRM, researches have been mainly focused on the effects on the MOE as it could be easily compared to static measurements. However, the VRM allows measuring the damping, another mechanical property highly involved in vibratory phenomena. Few studies have been devoted to the sensitivity of the damping of samples submitted to a fungal activity.

The damping characterizes the ability of a structure to dissipate mechanical energy when it is subjected to cyclic loading. Its origin is associated with three classes of mechanisms related to the material, the boundaries conditions and the surrounding fluid (Woodhouse 1998). In wood science, this energy dissipation is frequently quantified by the logarithmic decrement $\delta_{\log }$ or the damping ratio $\xi$, which are both frequency dependent and related together by the following relation when $\xi \ll 1$ (Brancheriau 2002, p. 119):

$$
\delta_{\log } \approx 2 \pi \xi
$$

For dissipative linear structures with a single degree-of-freedom (SDOF system), which corresponds to the simplest vibrating mechanical system, the calculation of $\xi$ has been largely studied in case of free vibration (De Silva 2005, p. 16). However, the $\log$ on its elastic supports is a multiple degree-of-freedom system (MDOF system) that possesses several vibration modes. The analysis of this system is facilitated by considering the MDOF system as a superposition of SDOF systems (Ouis 2000). The vibratory response of the log is then studied for each vibration mode separately in order to determine the damping characteristics (Brancheriau 2002, p. 122).

Labonnote et al. (2013) itemised values of $\xi$ in the scientific literature from 1950 for several intact wood species. Species investigated in the different studies were mainly softwoods with moisture content (MC) below the FSP. The values are between 0.0022 and 0.0068 . The differences are due to diversities of species, anatomical orientations and the experimental conditions. Below FSP, MC has a 
significant effect on $\xi$ (Obataya et al. 1998; Yeh et al. 1971) as it is well known for other mechanical properties. $\xi$ increases when the MC rises. But $\xi$ behaviour has not been studied when the MC rises above FSP. Regarding the effects of decay on damping, Ouis (1999) mentioned no significant research. Dunlop (1983) released that decay leads to an increase in the damping of longitudinal acoustic waves. Ouis (2000) confirms this fact using a room acoustical technique to detect decay in logs. Bucur (2006) introduced the damping coefficient as an indicator of microstructural modifications but without mentioning the decay.

The aim of this study was to assess the decay effect of small-diameter silver fir $\operatorname{logs}(155 \mathrm{~cm}$ in length, $6-10 \mathrm{~cm}$ in diameter), on the damping and the MOE measured by the transverse vibration resonant method. An experiment has been set up in order to decay the small-diameter logs in a wide range. Their mechanical properties have been measured by the VRM before and after the decay process. First, the validity of the MOE and $\xi$ measurements is discussed by taking into account the geometric and material singularities of the logs. Then, the effect of decay on each of the properties is analysed. Finally, a combined analysis of the $\mathrm{MOE}$ and $\xi$ is proposed to consider the effect of decay.

\section{Materials and methods}

\section{Preparation of samples}

One hundred and ten small-diameter logs of silver fir (Abies alba) have been taken from an alpine forest located in Lagarde-en-Oisans (Isère-France). The pruned logs were $155 \mathrm{~cm}$ in length and had a mean diameter of $7.4 \mathrm{~cm}$ (Fig. 1), in order to obtain a length-to-diameter ratio around 18 according to the standard EN 14251 requirement (CEN 2003). The bark has been preserved in the same way as for the logs of the ecological engineering structures. For each log, the diameter corresponds to the mean diameter obtained from three measurements at both ends and in the middle.

\section{Degradation process}

The degradation process has been set up in a greenhouse to accelerate the decay kinetic. From $110 \operatorname{logs}$, 55 were buried in the greenhouse under a first layer of woody debris picked up in a silver fir forest and a second one of local soil layer (Fig. 1). The logs moisture content was kept above FSP by regular watering and checked with the resistive wood moisture sensor Humitest Timb plus (Domosystem). As a consequence, the moisture content of decayed samples, i.e. samples after the degradation process, was not controlled and might vary from one sample to the other. The samples have been collected from the greenhouse in four series after 138, 347,655 and 788 days of degradation. As the study was focused only on the decay extent, no distinction between samples according to their series was made. The kinetic of decay might actually change inside the greenhouse according to the logs position. 

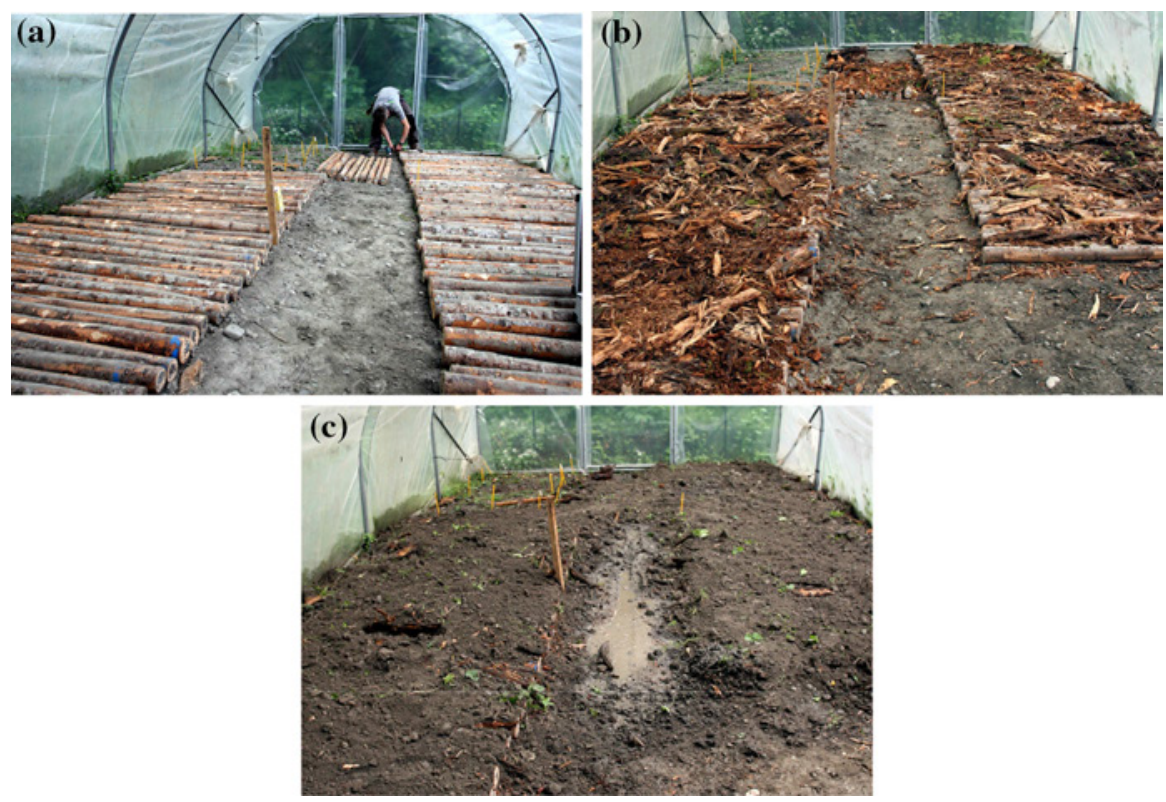

Fig. 1 Successive steps of sample preparation in the greenhouse: a The small-diameter logs laid on the ground. b The small-diameter logs covered by woody debris. c Samples covered by a local soil layer

\section{MC and specific gravity measurement}

The MC was measured on a $5 \mathrm{~cm}$-transversal slice of each sample in intact and decayed states. It was calculated according to Eq. 2. The result is a mean MC of the slice and does not take into account the potential variation of the MC along the sample.

$$
\mathrm{MC}=\left[\left(W_{h}-W_{0}\right) / W_{0}\right] \times 100
$$

where $W_{h}$ is the wet weight and $W_{0}$ is the oven-dry weight.

The oven-dry specific gravity (SG) was measured according to Williamson and Wiemann (2010) on the same $5 \mathrm{~cm}$-transversal slice used for the MC measurement. The volume measurement consists in immersing the sample in a container placed on a scale. The displayed mass thus corresponds to the volume of the sample. Before immersion and after weighing, the samples were covered by a grease layer as thin as possible to avoid rehydration. The SG was calculated with Eq. 3.

$$
\mathrm{SG}=\left(W_{0} / V_{0}\right) \times 100
$$

where $V_{0}$ is the oven-dry volume.

\section{MOE measurement of intact or decayed small-diameter logs}

The mechanical properties of the intact and decayed samples were estimated by dynamic measurements. The boundaries conditions of the sample on the test bench 
(Fig. 2a) allowed reproducing free-free transverse vibrations thanks to rubber bands supports. The supports were sufficiently elastic to neglect the effect of supports position on the MOE measurement. The small-diameter logs were positioned with an overhang of $10 \mathrm{~cm}$ at each extremity. A vertical impulse initiated the vibrations at $5 \mathrm{~cm}$ from one extremity. The vertical vibrational response was acquired at $5 \mathrm{~cm}$ from the other extremity with the piezoelectric accelerometer Deltraton type 4397 from Brüel and Kjær magnetised on a screw (Fig. 2b). The accelerometer was powered by Deltraton Power Supply WB 1372 and its signal converted by the analogue-to-digital converter PicoScope 4224 from Pico Technology. The digital signal was recorded with a sampling frequency of $20 \mathrm{kHz}$ and an acquisition duration of $1.638 \mathrm{~s}$. The frequency resolution was $0.6 \mathrm{~Hz}$.

The free vibrations occur theoretically in the vertical plane passing through the longitudinal axis of the samples. The first three modes were determined from a signal processing developed with R software (R Core Team 2016) and the signal package (Signal Developers 2015). The fast Fourier transform (FFT) of the signal was calculated to determine the frequency of each mode. The fundamental frequency, i.e. the frequency of the first mode of vibration, corresponds to the first most energetic peak of the FFT. The frequencies of the first three vibration modes were recorded and used to calculate the MOE values.

The MOE has been calculated based on both the Euler-Bernoulli and Timoshenko models. Euler-Bernoulli theory neglects the distortion caused by shear and the effects of the elastic supports. It gives the analytical expression of the MOE for beams with a high length $(l)$ to depth $(h)$ ratio $[l / h>20$ according to Brancheriau and Bailleres (2002)]:

$$
E_{n}=4 \pi^{2} \rho S L^{4} \frac{f_{n}^{2}}{I X_{n}}
$$

with $E_{n}$ the MOE calculated for the mode $n, I=\pi \cdot d^{4} / 64$ the moment of inertia with $d$ the mean diameter of the sample, $\rho$ the specific gravity at the sample MC, $S$ area of the cross section, $L$ the beam length, $f_{n}$ the natural frequency and $X_{n}$ specific coefficient: $X_{1}=500.5467, X_{2}=3803.14, X_{3}=14,619.72$. The modulus of elasticity $E_{n}$ has been assumed consistent in the whole beam.
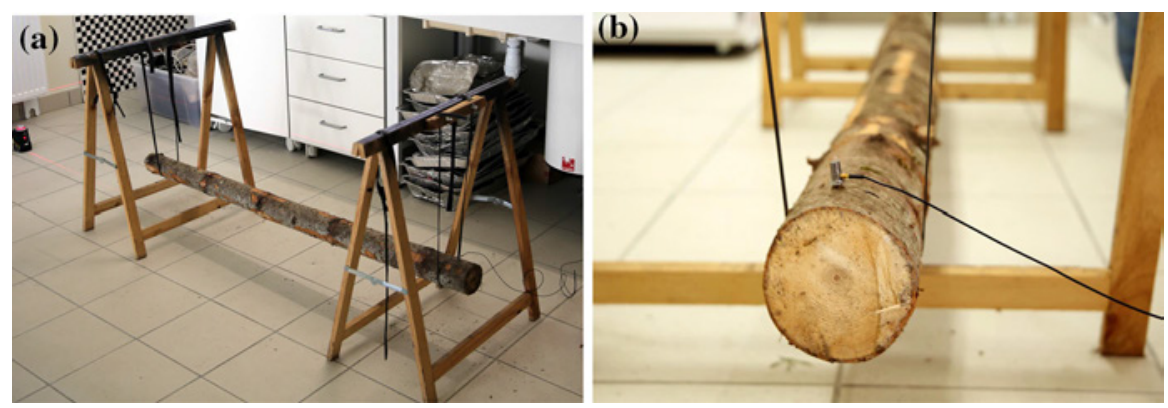

Fig. 2 a Small-diameter log prepared on the test bench for the dynamic test. b Accelerometer installed on the small-diameter log 
$E_{n}$ was, respectively, noted $E_{n}^{s}$ and $E_{n}^{d}$ for intact and decayed states. The normalized loss in $E_{n}$ of a sample, $D_{w \cdot E_{n}}$, is defined for the mode $n$ by:

$$
D_{w \cdot E_{n}}=\frac{E_{n}^{s}-E_{n}^{d}}{E_{n}^{s}}
$$

The Timoshenko theory takes into account the rotational inertia and the strain caused by shear. The effects of the elastic supports are still neglected. The modulus of elasticity is given for natural frequency $n$ by the solution of Bordonné (Brancheriau and Bailleres 2002):

$$
\frac{E_{\text {timo }}}{\rho}-\frac{E_{\text {timo }}}{K G}\left[\alpha F_{2}\left(m_{n}\right) 4 \pi^{2} \frac{S L^{4}}{I} \frac{f_{n}^{2}}{X_{n}}\right]=4 \pi^{2} \frac{S L^{4}}{I} \frac{f_{n}^{2}}{X_{n}}\left[1+\alpha F_{1}\left(m_{n}\right)\right]
$$

with $E_{\text {timo }}$ the MOE, $G$ the shear modulus, $I=\pi \cdot d^{4} / 64$ the moment of inertia with $d$ the mean diameter of the sample, $\rho$ the specific gravity, $S$ the area of the cross section, $L$ the beam length, $f_{n}$ the natural frequency, $X_{n}=m_{n}^{4}, K$ the shear correction factor, $m_{n}$ the solution of the equation $\cos \left(m_{n}\right) \operatorname{ch}\left(m_{n}\right)=1$ and

$$
\begin{gathered}
F_{1}\left(m_{n}\right)=\theta^{2}\left(m_{n}\right)+6 \theta\left(m_{n}\right) \\
F_{2}\left(m_{n}\right)=\theta^{2}\left(m_{n}\right)-2 \theta\left(m_{n}\right) \\
\theta\left(m_{n}\right)=m_{n} \frac{\tan \left(m_{n}\right) \tanh \left(m_{n}\right)}{\tan \left(m_{n}\right)-\tanh \left(m_{n}\right)}
\end{gathered}
$$

The modulus of elasticity $E_{\text {timo }}$ has been assumed consistent in the whole beam. $E_{\text {timo }}$ is, respectively, noted $E_{\text {timo }}^{s}$ and $E_{\text {timo }}^{d}$ for intact and decayed states. The normalized loss in $E_{\text {timo }}$ of a sample is defined for the mode $n$ by:

$$
D_{w \cdot E_{\mathrm{timo}}}=\frac{E_{\mathrm{timo}}^{s}-E_{\mathrm{timo}}^{d}}{E_{\mathrm{timo}}^{s}}
$$

\section{Damping ratio $\xi$ measurement of intact or decayed small-diameter logs}

It was assumed that the small-diameter log behaved like an underdamped system submitted to viscously damped free vibrations. This system with multiple degreesof-freedom has several modes of vibration and equates to a superposition of dissipative linear structures with single degree-of-freedom (SDOF system) associated with each mode (Brancheriau 2002, p. 120). Thus, for each mode, the raw acceleration signal was filtered in spectral domain by a pass-band Tchebychev filter centred on the frequency of the considered mode. As a result, the filtered acceleration signal in temporal domain decreased exponentially over time (Thomson and Dahleh 1998) and its outer envelope $a_{\max }$ was temporally governed by Eq. 11 for the pulsation $\omega_{n}$. 


$$
a_{\max }(t)=A \mathrm{e}^{-\xi_{n} \omega_{n} t}
$$

where $n$ is the number of the mode, $\xi_{n}$ is the damping ratio, $A$ is a constant and $\omega_{n}$ the fundamental pulsation.

$\xi$ was estimated by a curve-fitting method: the natural logarithm of $a_{\max }(t)$ was fitted by a linear regression. $\xi$ is defined as the ratio of the slope of the regression line and the fundamental pulsation $\omega_{n} . \xi_{n}^{i}$ and $\xi_{n}^{d}$ were, respectively, the damping ratio of a sample in intact and decayed states. The normalized gain in $\xi$ of a sample was defined by:

$$
D_{w \cdot \xi_{n}}=\frac{\xi_{n}^{d}-\xi_{n}^{s}}{\xi_{n}^{d}}
$$

Comparison $D_{w \cdot \xi_{n}}$ versus $D_{w \cdot E_{n}}$ and versus $D_{w \cdot E_{\text {timo }}}$

$D_{w \cdot \xi_{n}}, D_{w \cdot E_{n}}$ and $D_{w \cdot E_{\text {timo }}}$ were first graphically compared with boxplots that summarize the minimum and maximum of dataset, the quartiles, the median and, if any, the outliers. The relationships between $D_{w \cdot \xi_{n}}$ versus $D_{w \cdot E_{n}}$ and versus $D_{w \cdot E_{\text {timo }}}$ were tested by a linear regression and quantified through its coefficient of determination $r^{2}$.

\section{Results}

\section{Specific gravity measurement}

On average, the SG is $463 \mathrm{~kg} \mathrm{~m}^{-3}$ for intact samples and $397 \mathrm{~kg} \mathrm{~m}^{-3}$ for decayed samples. The SD of decayed samples increases from 53 to $65 \mathrm{~kg} \mathrm{~m}^{-3}$ compared to SD of intact samples.

\section{MOE measurement of intact or decayed small-diameter logs}

For intact and most of decayed samples, the first three modes were always identified. The third mode was not identified for 12 decayed samples (Table 1). Furthermore, depending on the log, the identification of the natural frequency on the FFT might be disturbed by peaks very close to the main one (see peak 2 in Fig. 3). In this case, the retained value was the higher peak. The FFT of intact and decayed samples, whose MC was different, differed mainly by positive or negative frequency shifts for a considered mode. The peaks intensities were also affected. The natural frequencies of intact and decayed samples, although different for the same sample, were in the same range: the differences of their mean values were lower than $11 \mathrm{~Hz}$, i.e. $3 \%$ of the frequency value (Table 1). The standard deviations (SD) were significantly higher for the decayed samples (mode 1: $\mathrm{SD}_{d}=\mathrm{SD}_{s}+10 \mathrm{~Hz}$, mode 2: $\mathrm{SD}_{d}=\mathrm{SD}_{s}+21 \mathrm{~Hz}$, mode 3: $\left.\mathrm{SD}_{d}=\mathrm{SD}_{s}+22 \mathrm{~Hz}\right)$. 
Table 1 Physical and mechanical measurements of silver fir samples

\begin{tabular}{|c|c|c|c|c|c|c|c|c|c|c|}
\hline & \multicolumn{5}{|c|}{ Intact samples } & \multicolumn{5}{|c|}{ Decayed samples } \\
\hline & Mean & Min. & Max. & SD & $N_{e}$ & Mean & Min. & Max. & SD & $N_{e}$ \\
\hline $\mathrm{MC}(\%)$ & 147 & 43 & 197 & 30 & 108 & 37 & 26 & 67 & 9 & 55 \\
\hline $\begin{array}{l}\text { Specific gravity } \\
\qquad\left(\mathrm{kg} \mathrm{m}^{-3}\right)\end{array}$ & 463 & 354 & 626 & 53 & 108 & 397 & 252 & 554 & 65 & 55 \\
\hline Freq $1(\mathrm{~Hz})$ & 85 & 48 & 128 & 16 & 108 & 84 & 39 & 154 & 26 & 55 \\
\hline Freq $2(\mathrm{~Hz})$ & 223 & 128 & 324 & 40 & 108 & 226 & 110 & 392 & 61 & 54 \\
\hline Freq $3(\mathrm{~Hz})$ & 412 & 236 & 574 & 69 & 108 & 401 & 199 & 587 & 91 & 43 \\
\hline E1 (MPa) & 9231 & 5762 & 13,634 & 1568 & 108 & 4625 & 876 & 10,405 & 2201 & 55 \\
\hline$E 2(\mathrm{MPa})$ & 8392 & 5464 & 12,336 & 1353 & 108 & 4378 & 911 & 8818 & 1888 & 54 \\
\hline E3 (MPa) & 7507 & 5158 & 11,235 & 1186 & 108 & 3784 & 864 & 7538 & 1507 & 43 \\
\hline Etimo (MPa) & 9658 & 5801 & 14,001 & 1781 & 80 & 4728 & 898 & 11,213 & 2282 & 52 \\
\hline$\xi 1(-)$ & 0.0050 & 0.0037 & 0.0076 & 0.0007 & 108 & 0.0086 & 0.0045 & 0.0189 & 0.0033 & 55 \\
\hline$\xi 2(-)$ & 0.0053 & 0.0040 & 0.0078 & 0.0006 & 108 & 0.0096 & 0.0036 & 0.0191 & 0.0036 & 54 \\
\hline$\xi 3(-)$ & 0.0057 & 0.0042 & 0.0080 & 0.0006 & 108 & 0.0110 & 0.0017 & 0.0207 & 0.0038 & 43 \\
\hline
\end{tabular}

Range and standard deviation (SD)

Freq $n$ the natural frequency of mode $n, E_{n}$ the MOE calculated from Euler Bernoulli model for mode $n$, $E_{\text {timo }}$ the MOE calculated from Timoshenko model, $\xi_{n}$ the damping ratio of mode $n, N_{e}$ the number of samples

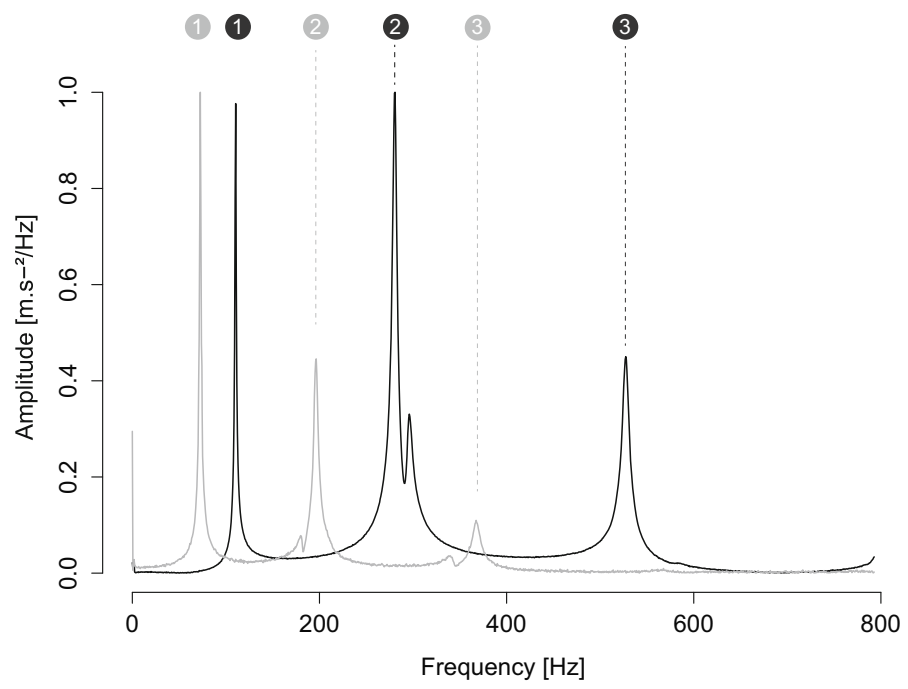

Fig. 3 FFT of the same sample in intact (black line) and decayed (grey line) states. The three first modes were identified

For the intact samples, the average of $E_{n}$ decreased from 9231 (mode 1) to $8392 \mathrm{MPa}$ (mode 2) and to $7508 \mathrm{MPa}$ (mode 3) (Table 1). $E_{\text {timo }}$ was of $9657 \mathrm{MPa}$ on average. For the decayed samples, the modulus was significantly lower (Fig. 4). The average of $E_{n}$ was of 4625,4378 and $3784 \mathrm{MPa}$ for, respectively, mode 1, 


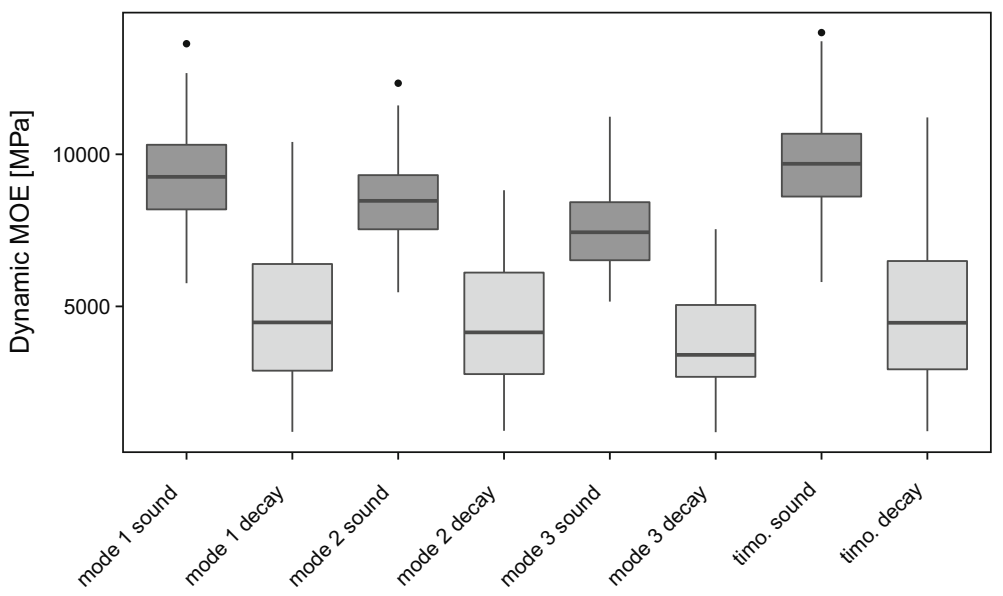

Fig. 4 Dynamic MOE of intact (black) and decayed samples (grey)

mode 2 and mode 3 . The average of $E_{\text {timo }}$ was of $4728 \mathrm{MPa}$. The Wilcoxon signedrank test applied to intact and decayed $E_{n}$ for each mode gave significantly low $p$ value of $1.13 \mathrm{e}-10,1.67 \mathrm{e}-10$ and $2.27 \mathrm{e}-13$ for modes 1,2 and 3 . For $E_{\text {timo, }}$, the $p$ value was of $3.61 \mathrm{e}-10$.

\section{Damping ratio $\xi$ measurement of intact or decayed small-diameter logs}

For a considered mode, the presence of multi-peaks in the FFT of the signal indicated the presence of secondary modes of lesser intensities and induced in particular by the geometrical irregularities of the samples. As a result, the signal damping presented oscillations (Fig. 5a) depending on the samples and the modes. As the damping did not follow an exponential law, the natural logarithm of $a_{\max }(t)$ was noisy (Fig. 5b). However, the coefficients of determination $R^{2}$ were high for all

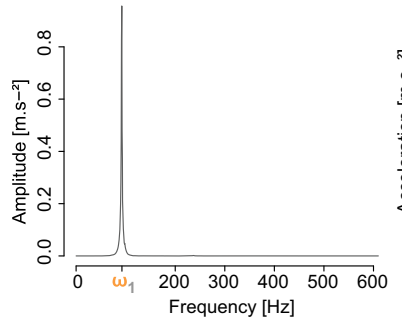

(a)

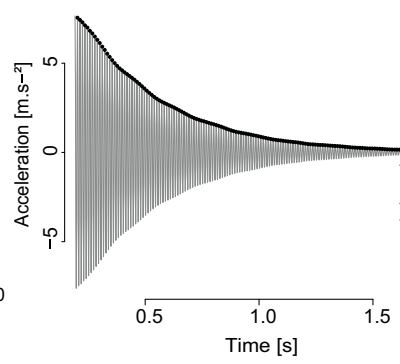

(b)

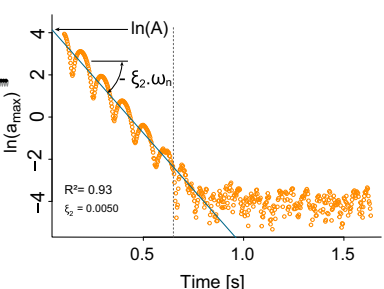

(c)

Fig. 5 Successive steps of the signal numerical treatment for $\xi$ calculation. Example is given for mode 1. a FFT of the raw signal filtered by a pass-band filter centred on $\omega_{1}(92.2 \mathrm{~Hz})$. b First mode filtered acceleration (grey curve) and the maxima $a_{\max }(t)$ (black dots). c Natural logarithm of the maxima $\ln \left(a_{\max }(t)\right)$ with its linear regression. The slope of this regression divided by the pulsation $\omega_{1}$ allows to calculate $\xi_{1}$ 


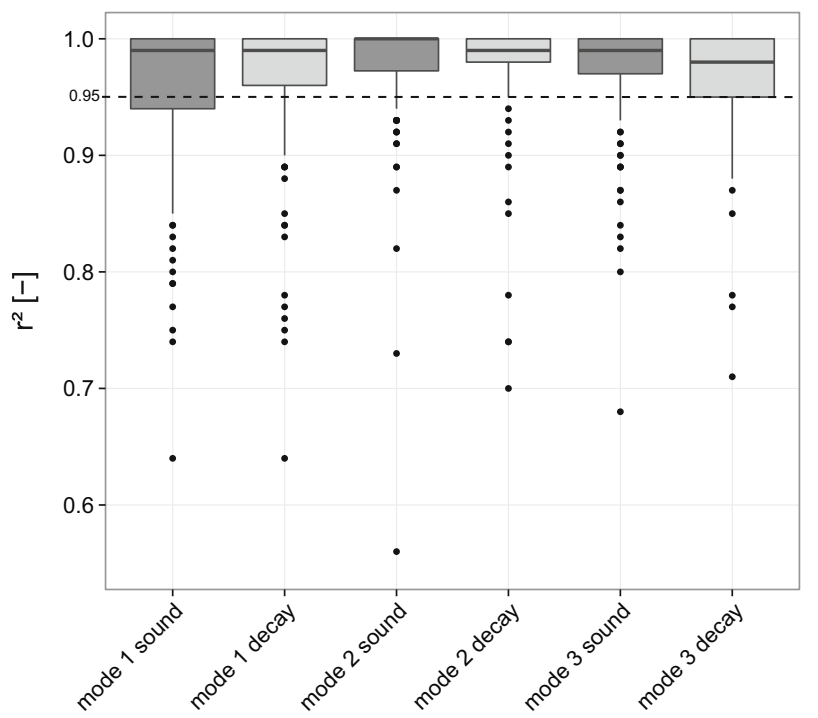

Fig. 6 Coefficient of determination $R^{2}$ of damping ratio $\xi_{n}$ calculated for intact and decayed samples

modes (Fig. 6). For modes 1, 2 and 3 of intact samples, respectively, 73, 83 and $74 \%$ of $R^{2}$ were higher than 0.95 . For modes 1,2 and 3 of decayed samples, 73, 89 and $74 \%$ of $R^{2}$ were higher than 0.95 . Mode $2 R^{2}$ was the highest with an average of 0.98 compared to 0.96 for other modes. Furthermore, it was observed that the damping ratio (DR) increases with the mode order. The increase from one mode to the other was higher for decayed samples: on average, $11.5 \%$ compared to the $6.5 \%$ for intact samples. No correlation has been found between MC and $\xi_{n}$ whatever mode (Fig. 7).

The average of $\xi^{d}$ was significantly higher than the average of $\xi^{i}$ (Fig. 8; Table 1): 0.0050 for $\xi_{1}^{i}$ and 0.0086 for $\xi_{1}^{d}, 0.0053$ for $\xi_{2}^{i}$ and 0.0096 for $\xi_{2}^{d}, 0.0057$ for $\xi_{3}^{i}$ and 0.0110 for $\xi_{3}^{d}$. The coefficient of variation represented, respectively, 14, 11 and $11 \%$ of $\xi_{1}^{i}, \xi_{2}^{i}$ and $\xi_{3}^{i}$. It was lower than SD of $\xi^{d}$, that represents 38,38 and

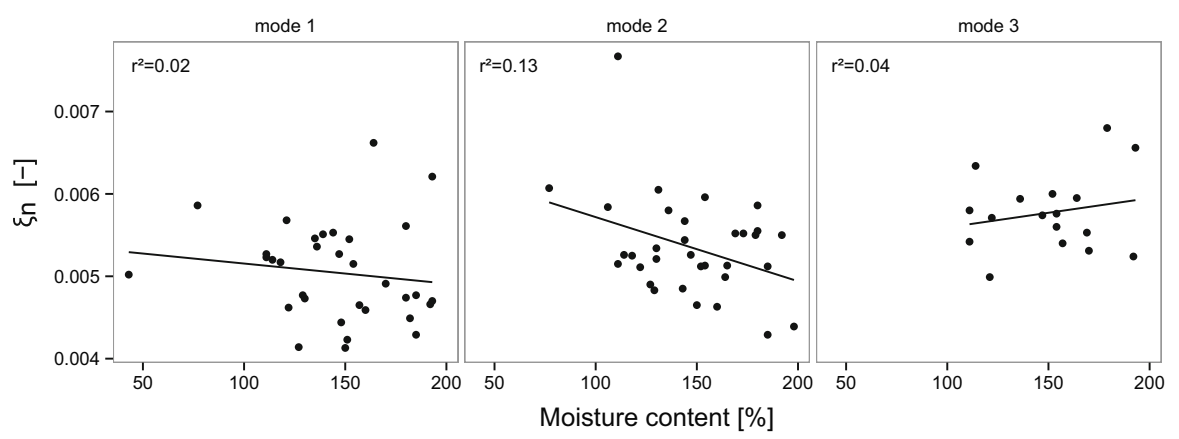

Fig. 7 Damping ratio $\xi_{n}$ of the intact samples against moisture content 


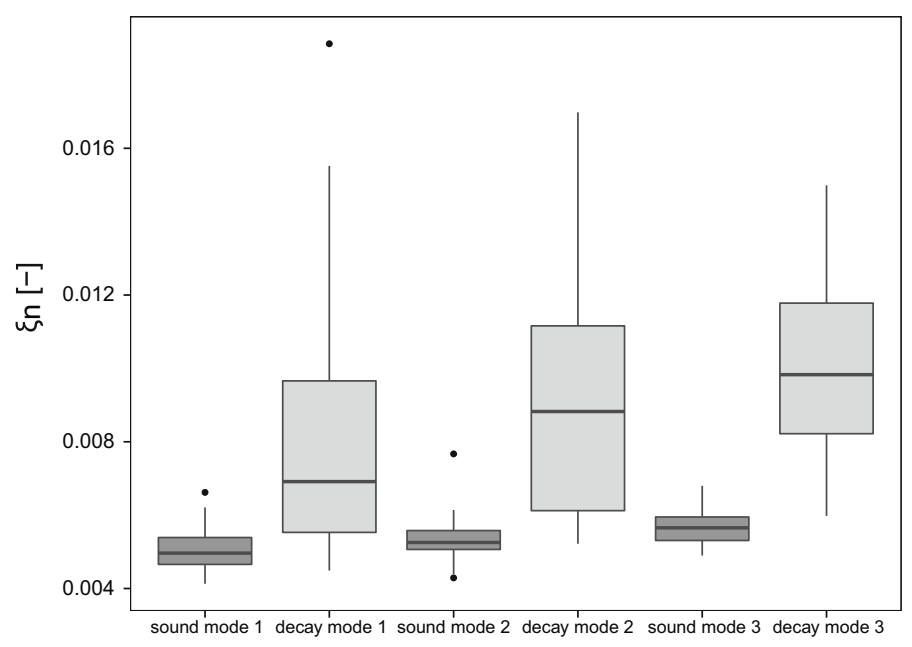

Fig. 8 Damping ratio $\xi_{n}$ of intact and decayed samples calculated for the first three modes of vibration

$35 \%$ of $\xi_{1}^{d}, \xi_{2}^{d}$ and $\xi_{3}^{d}$. The Wilcoxon signed-rank test applied to intact and decayed $\xi$ gave significantly low $p$ value of $1.07 \times 10 \mathrm{e}^{-06}, 2.9 \times 10^{-11}$ and $1.7 \times 10^{-07}$ for mode 1,2 and 3.

\section{Comparison $D_{w \cdot \xi_{n}}$ versus $D_{w \cdot E_{n}}$ and versus $D_{w \cdot E_{\text {timo }}}$}

For all modes, $D_{w \cdot E_{n}}$ and $D_{w} \cdot E_{\text {timo }}$ were in the same range (Fig. 9). The authors noticed $D_{w \cdot \xi_{1}}$ has a lower mean value $(0.30)$ than $D_{w \cdot E_{1}}(0.45)$ or than $D_{w \cdot E_{\text {timo }}}(0.50)$. Similar observations have been done for the two other modes. The comparison between $D_{w \cdot \xi_{n}}$ and $D_{w \cdot E_{n}}$ showed a strong relationship in mode $1\left(R_{\mathrm{m} 1}^{2}=0.72\right)$ and weaker for the others $\left(R_{\mathrm{m} 2}^{2}=0.55, R_{\mathrm{m} 3}^{2}=0.55\right)$ (Fig. 10). In mode 1 , the analytical

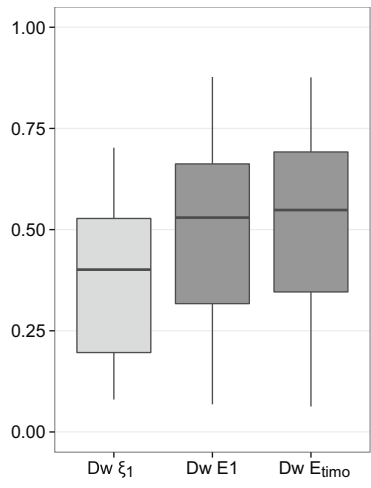

(a)

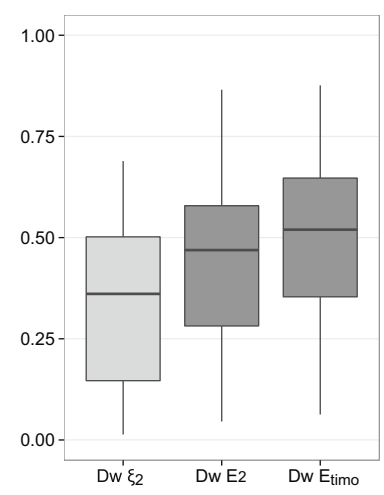

(b)

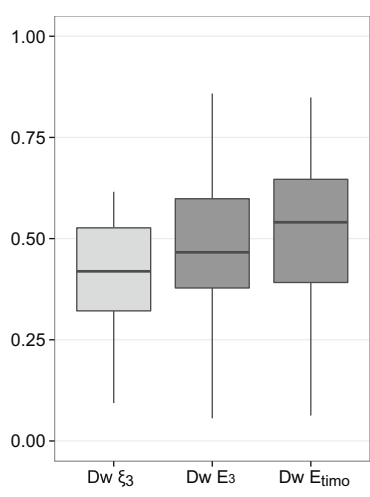

(c)

Fig. 9 Indicators $D_{w}$ for mode 1 (a), mode 2 (b) and mode 3 (c) 


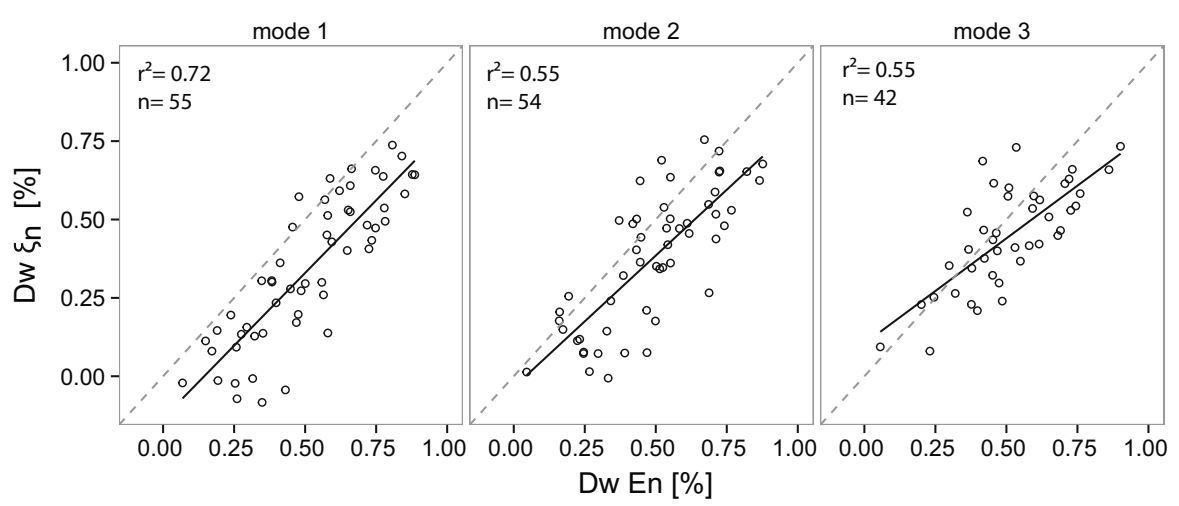

Fig. 10 Relation between $D_{w \cdot E_{n}}$ and $D_{w} \cdot \xi_{n}$

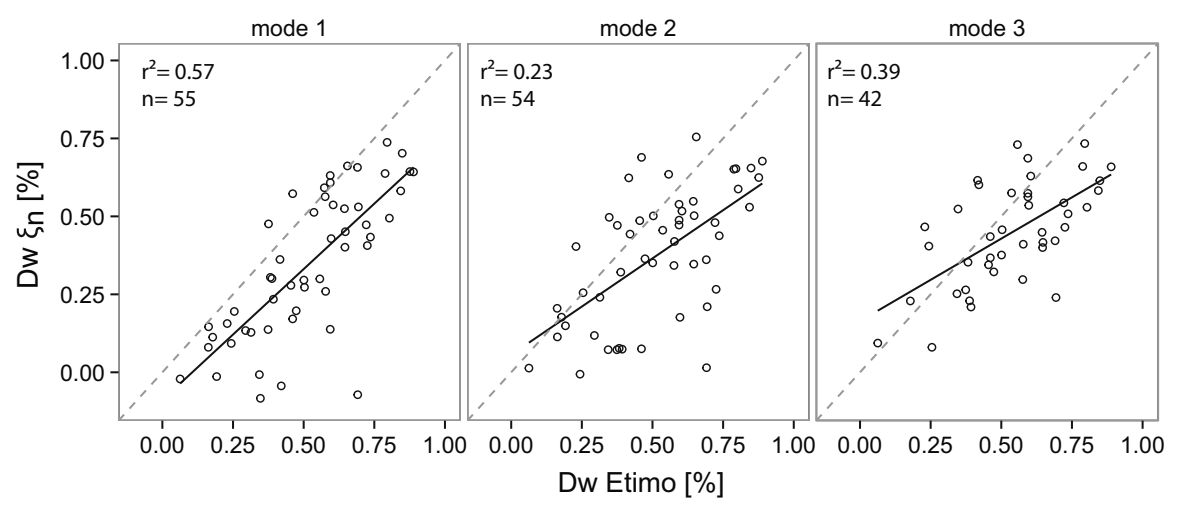

Fig. 11 Relation between $D_{w \cdot E_{\text {timo }}}$ and $D_{w} \cdot \xi_{n}$

expression of the regression line was $y=0.93 x-0.13$. It was noticed the constant shift of 0.13 between $D_{w \cdot \xi_{1}}$ and $D_{w \cdot E_{1}}$. The comparison with $D_{w \cdot E_{\text {timo }}}$ did not reach the same level. The correlation coefficient was at most of 0.57 (mode 1) (Fig. 11).

\section{Discussion}

As outlined in the introduction, some studies showed that the VRM is effective to measure the MOE on intact logs. Others tested the VRM to assess the MOE of small squared small-diameter logs in wood decay testing. However, more work was needed to test the effects of decay on elastic and damping properties of smalldiameter logs measured by the VRM. Significant differences were found between the MOE and $\xi$ measured on silver fir small-diameter logs before and after the decay process. Moreover, the normalized loss of the MOE and $\xi$ were surprisingly proportional. 


\section{Reliability of MOE and $\xi$ measurements of intact small-diameter logs}

It is necessary as a preamble to precise that the MOE calculation is based on a simplified assumption regarding the homogeneity of the wood properties. In Eqs. 4 and 6, the intrinsic variation of MOE generated by the presence of defects and differences of wood structure is not considered. Thus, $E_{n}$ and $E_{\text {timo }}$ shall be understood as estimations of the modulus of elasticity.

Effect of geometric singularities The singularities of the small-diameter logs disturbed the vibratory response to a limited extent. For a clear circular wooden beam loaded in a vertical plane, vibrations occur in this plane. Since the logs had no straight neutral fibre and the applied impulse was not strictly vertical, out-of-plane vibrations modes were activated as it can be deduced from the presence of multipeaks in the FFT (Fig. 3 peak 2). Considering the vertical loading of the log, it was assumed that the most energetic peak belongs to the vertical vibrations. The out-ofplane vibrations modes had limited consequences on the MOE measurement. Coherent values of MOE in green state were obtained according to references yielded by the literature (Table 2). $E_{\text {timo }}(9658 \mathrm{MPa})$ and $E_{1}(9231 \mathrm{MPa})$ were between those measured for four fresh logs by Lundström et al. (2008) (11,500 MPa on average) and those indicated by Niklas and Spatz (2010) (8100 MPa). Another comparison is also possible with values of MOE measured at $12 \% \mathrm{MC}$, i.e. MC prescribed by standards. MOE difference between measurements in green and $12 \%$ states is about $18 \%$ for common softwoods (Table 2). The same comparison was established taking a $12 \%$ mean $\mathrm{MOE}$ of $12,438 \mathrm{MPa}$, not forgetting that discrepancies established between the different values are huge and mainly due to species variability, $3000 \mathrm{MPa}$ according to Tropix database Cirad (2015). Finally, MOE difference between both MC was coherent for both theories. It was $22 \%$ for $E_{\text {timo }}, 26 \%$ for $E_{1}$ (see details in Table 2). Furthermore, the influence of out-of-plane

Table 2 Comparison between the MOE measured in green state $(\mathrm{MC}>30 \%)$ and at $12 \%$ of moisture content for common softwoods

${ }^{1}$ From Kretschmann (2010),

${ }^{2}$ from Cirad (2015), ${ }^{3}$ from Haines et al. (1996), ${ }^{4}$ from Verkasalo and Leban (2002),

5 from Niklas and Spatz (2010),

${ }^{6}$ from Lundström et al. (2008),

${ }^{7}$ cf $E_{\text {timo }}$ Table $1,{ }^{8}$ cf $E_{1}$ Table 1

\begin{tabular}{llll}
\hline & \multicolumn{2}{l}{ MOE (MPa) } & Variation (\%) \\
\cline { 2 - 3 } & $12 \%$ & Green & \\
\hline Silver fir & $14,300^{2}$ & - & - \\
& $12,500^{3}$ & - & - \\
Mean & $10,515^{4}$ & - & - \\
Silver fir & 12,438 & - & - \\
& 12,438 & $8100^{5}$ & -34 \\
& 12,438 & $11,500^{6}$ & -8 \\
Sitka spruce & 12,438 & $9658^{7}$ & -22 \\
Pacific silver fir & 11,438 & $9231^{8}$ & -26 \\
Western larch & $11,300^{1}$ & $9400^{1}$ & -16 \\
Douglas fir & $14,300^{1}$ & $9300^{1}$ & -17.7 \\
Mean & $13,600^{1}$ & $11,400^{1}$ & -20.3 \\
\hline
\end{tabular}


modes on $\xi_{n}$ measurements remained limited. The damping was affected in varying proportions by out-of-plane modes depending on the intensities of the secondary peaks. The acceleration damping deviated from an exponential decrease when the secondary peaks are of high intensity (Fig. 5a). However, the quality of $\xi_{n}$ measurement was high according to the determination coefficients values, especially for the second mode (Fig. 6).

Effect of moisture content For wood above FSP, $\xi_{n}$ was found to be independent of MC. No correlation has been found between MC and $\xi$ (Fig. 7). As a consequence, the difference of MC of a log between measurements taken before and after the decay process did not prevent the comparison between $\xi_{n}^{i}$ and $\xi_{n}^{d}$.

\section{Effects of decay on MOE and $\xi$ measurements of small-diameter logs}

The variation of MOE generated by the random development of fungi is not considered in Eqs. 4 and 6. As a consequence, $E_{n}$ and $E_{\text {timo }}$ shall be understood as equivalent moduli of elasticity.

For a given mode, a shift distinguishes natural frequencies of intact and decayed states (Fig. 3). According to Eq. 4, two factors explain this shift: the loss in MOE induced by decay and the variations in logs mass as the MC was not controlled in the greenhouse. Thus, the natural frequencies do not give directly relevant information on decay. The calculation of $E_{\text {timo }}$ and $E_{n}$ allows to overcome the mass variations.

Regardless of the mode, a significant effect of decay on $E_{n}$ or $E_{\text {timo }}$ has been noted (Fig. 4). The VRM has measured the decrease in MOE due to decay even for small-diameter logs decayed by a microbial community. On that basis, it is proposed to define $D_{w \cdot E_{n}}$ and $D_{w \cdot E_{\text {timo }}}$ as references to quantify the effect of decay on the smalldiameter logs. Thus, defined as normalized differences, these two indicators limit the consequences of simplifying assumptions related to the small-diameter logs characteristics such as consideration of a mean diameter.

These results confirm that the damping ratio increases when wood is submitted to fungal activity. $\xi_{n}^{i}$ and $\xi_{n}^{d}$ remained actually comparable as the frequency dependence of $\xi_{n}$ is limited for frequencies below $1000 \mathrm{~Hz}$ (Gibson 1989; Holz 1996). The sensitivity of damping to decay has been quantified by the indicator $D_{w \cdot \xi_{n}}$ (Fig. 9).

\section{Comparison $D_{w} \cdot \xi_{n}$ versus $D_{w \cdot E_{n}}$ and versus $D_{w} \cdot E_{\text {timo }}$}

As shown above, the effect of decay on $\xi_{n}^{i}, E_{n}$ and $E_{\text {timo }}$ was measurable by the VRM. The $\xi_{n}^{i}$ and MOE values gave inherently information about the decay extent thanks to significant properties variations between intact and decayed states. But the variability of these properties is so high for silver fir [SD of MOE at $12 \%$ : $3000 \mathrm{MPa}$ - (Cirad 2015)] that this observation should be limited to this study. Furthermore, the decay increases the heterogeneity of the properties that reduces the accuracy of measurement. As a consequence, to avoid the adverse effects of the variability, the assessment of decay extent by means of indicators $D_{w} \cdot \xi_{n}$ and $D_{w} \cdot E_{n}$ is 
more relevant. Moreover, these indicators varied proportionally. This relationship was especially strong in mode 1 between $D_{w \cdot E_{1}}$ and $D_{w \cdot \xi_{1}}\left(R^{2}=0.72\right)$ (Fig. 10). Even if the second mode of vibrations was better for $\xi$ calculation, the first mode was more relevant to assess decay in small-diameter logs. Concretely, $D_{w} \cdot \xi_{1}$ underestimated the decay by $0.13 \%$ against $D_{w \cdot E_{1}}$. Thus, $D_{w \cdot \xi_{1}}$ could be an alternative to quantify decay instead of $D_{w \cdot E_{1}}$ when neither the mass nor the geometrical characteristics of samples are known. This result raises, however, the question of the frequency influence on the relationship as the best results have been obtained with quite low frequencies $(48 \mathrm{~Hz}<$ Freq $1<128 \mathrm{~Hz})$. Further investigations must be conducted to assess whether the results are still significant for smalldiameter logs vibrating at different ranges of frequency.

\section{Potential of the VRM}

From these results, the VRM can meet the expectations of practitioners who seek to assess the decay extent by a quantitative and repeatable measurement. Actually, the method proposed by the standard EN 252 (CEN 2014), to assess the extent of decay of samples decayed in the field, is based on a qualitative approach. The assessment combines a visual inspection with a superficial assessment of the hardness and requires the debarking of samples. It is true that EN 252 refers to the possibility of assessing decay by the loss of MOE, but it highlights the difficulty of measuring the ratio normatively due to the geometrical changes of the sample and its variation in moisture content. This study shows the VRM is a promising solution for assessing degradation of field degraded samples in quantitative terms. As EN 252 serves actually as a benchmark to assess the decay extent of samples decayed in the field, it would be necessary to perform a comparison of both methods. Furthermore, the VRM imposes measurements under particular support conditions allowing the free vibrations of the sample. For compatibility with the evaluation of the degradation of structural elements of a structure, it can be considered making measurements on removable test specimens placed at different points of the structure during its construction. The monitoring of these test samples from the intact state would make it possible to inform the practitioner about the structural conditions of the logs.

\section{Conclusion}

This study aims to investigate the potential of a non-destructive method to assess the decay extent in wooden small-diameter logs. The effect of fungal activity on the module of elasticity (MOE) and the damping ratio $\xi$ of silver fir small-diameter logs was investigated using the vibration resonant method (VRM). Experiments confirm that the VRM measures coherent MOE values with both Euler-Bernoulli and Timoshenko theories despite geometric and material singularities. The study also points out that the moisture content (MC) has no influence on $\xi$ for wood MC above the fibre saturation point. 
In addition, the study shows the significant effect of the fungal activity on MOE and $\xi$ assessed by the VRM. MOE decreases and $\xi$ increases when wood is subjected to decay. Besides, the study highlights that their normalized variations $D_{w \cdot \xi_{n}}, D_{w \cdot E_{n}}$ and $D_{w \cdot E_{\text {timo }}}$ change proportionally, especially for $D_{w \cdot \xi_{1}}, D_{w \cdot E_{1}}$ (first mode of vibrations: $R^{2}=0.72$ ). This initial work confirmed the VRM as an effective method to quantify the decay extent in logs. Furthermore, $D_{w \cdot \xi_{n}}$ is promising for logs whose mass nor geometric characteristics are known. Researches dedicated to the influence of the first-mode frequency value and the logs size are of interest to confirm the potential of the method. Finally, the assessment by the VRM may be considered for other applications provided that comparative tests between assessments with the VRM and the standard EN 252 are made.

Acknowledgements This work has been financed within the framework of Arc Environnement (Rhône Alpes Region, France).

\section{References}

Alfredsen G, Larnoy E, Militz H (2006) Dynamic MOE testing of wood: the influence of wood protecting agents and moisture content on ultrasonic pulse and resonant vibration. Wood Res 51(1):11-20

Barré JB, Bourrier F, Cécillon L, Brancheriau L, Bertrand D, Thévenon MF, Rey F (2017) Predicting mechanical degradation indicators of silver fir wooden strips using near infrared spectroscopy. Eur J Wood Prod. doi:10.1007/s00107-017-1209-4

Barrett JD, Hong JP (2009) Moisture content adjustments for dynamic modulus of elasticity of wood members. Wood Sci Technol 44(3):485-495

Brancheriau L (2002) Expertise mecanique des sciages par analyses des vibrations dans le domaine acoustique (Dynamic analysis of sawing wood for strength grading). Ph.D. thesis, Université de la Méditerranée - Aix-Marseille II (In French)

Brancheriau L, Bailleres H (2002) Natural vibration analysis of clear wooden beams: a theoretical review. Wood Sci Technol 36(4):347-365

Brischke C, Rapp AO (2008) Influence of wood moisture content and wood temperature on fungal decay in the field: observations in different micro-climates. Wood Sci Technol 42(8):663

Bucur V (2006) Acoustics of wood. Springer, Berlin

CEN (2003) EN 14251:2003. Structural round timber. Test methods. Technical report, Brussels, Belgium

CEN (2006) EN 15083-1:2005. Determination of the natural durability of solid wood against wooddestroying fungi-test methods. Technical report, Brussels, Belgium

CEN (2014) EN 252:2013. Field test method for determining the relative protective effectiveness of a wood preservative in ground contact. Technical report, CEN, Brussels, Belgium

Cirad (2015) Tropix 7 version 7.5.1. doi:10.18167/74726f706978

Cruz H, Yeomans D, Tsakanika E, Macchioni N, Jorissen A, Touza M, Mannucci M, Loureno P (2015) Guidelines for on-site assessment of historic timber structures. Int J Archit Herit 9(3):277-289

Curling S, Clausen C, Winandy J (2002) Relationships between mechanical properties, weight loss, and chemical composition of wood during incipient brown-rot decay. Forest Prod J 52(7-8):34-39

De Silva CW (ed) (2005) Vibration and shock handbook. Mechanical engineering series. Taylor \& Francis, Boca Raton

Dunlop JI (1983) Testing of poles by acoustic resonance. Wood Sci Technol 17(1):31-38

Gibson RF (1989) Vibration-test methods for dynamic-mechanical-property characterization. In: Pendleton RL, Tuttle ME (eds) Manual on experimental methods for mechanical testing of composites. Springer, Berlin, pp 151-164

Green D, Gorman T, Evans J, Murphy J (2006) Mechanical grading of round timber beams. J Mater Civ Eng 18(1):1-10

Grinda M, Göller S (2005) Some experiences with stake tests at BAM test fields and in the BAM fungus cellar. Part 1: Comparison of results of visual assessments and determinations of static modulus of 
elasticity (MOE). Document IRG/WP 05-20319. International Research Group on Wood Protection, p 28

Haines D, Leban JM, Herb C (1996) Determination of Young's modulus for spruce, fir and isotropic materials by the resonance flexure method with comparisons to static flexure and other dynamic methods. Wood Sci Technol 30(4):253-263

Holz D (1996) Tropical hardwoods used in musical instruments - can we substitute them by temperate zone species? Holzforschung 50(2):121-129

Kretschmann D (2010) Mechanical properties of wood. In: Ross R (ed) Wood handbook: wood as an engineering material, chap 5. U.S. Department of Agriculture, Forest Service, Forest Products Laboratory, Madison

Labonnote N, Ronnquist A, Malo KA (2013) Experimental evaluations of material damping in timber beams of structural dimensions. Wood Sci Technol 47(5):1033-1050

Lundström T, Stoffel M, Stöckli V (2008) Fresh-stem bending of silver fir and Norway spruce. Tree Physiol 28(3):355-366

Machek L, Militz RH, Sierra A (2001) As the influence of wood moisture content on dynamic modulus of elasticity measurements in durability testing. Holzforschung Holzverwertung 53(5):97-100

Niklas KJ, Spatz HC (2010) Worldwide correlations of mechanical properties and green wood density. Am J Bot 97(10):1587-1594

Noetzli K, Boell A, Graf F, Sieber T, Holdenrieder O (2008) Influence of decay fungi, construction characteristics, and environmental conditions on the quality of wooden check-dams. Forest Prod J 58(4):72-79

Obataya E, Norimoto M, Gril J (1998) The effects of adsorbed water on dynamic mechanical properties of wood. Polymer 39(14):3059-3064

Ouis D (1999) Vibrational and acoustical experiments on logs of spruce. Wood Sci Technol 33(2): $151-184$

Ouis D (2000) Detection of decay in logs through measuring the dampening of bending vibrations by means of a room acoustical technique. Wood Sci Technol 34(3):221-236

Previati M, Canone D, Bevilacqua I, Boetto G, Pognant D, Ferraris S (2012) Evaluation of wood degradation for timber check dams using time domain reflectometry water content measurements. Ecol Eng 44:259-268

R Core Team (2016) R: a language and environment for statistical computing. R Foundation for Statistical Computing, Vienna, Austria. https://www.R-project.org/

Riggio M, Anthony RW, Augelli F, Kasal B, Lechner T, Muller W, Tannert T (2013) In situ assessment of structural timber using non-destructive techniques. Mater Struct 47(5):749-766

Sandak A, Sandak J, Riggio M (2015) Assessment of wood structural members degradation by means of infrared spectroscopy: an overview. Struct Control Health Monit. doi:10.1002/stc.1777

Signal Developers (2015) Signal: signal processing. http://r-forge.r-project.org/projects/signal/

Stapel P, van de Kuilen JWG (2013) Effects of grading procedures on the scatter of characteristic values of European grown sawn timber. Mater Struct 46(9):1587-1598

Tannert T, Anthony RW, Kasal B, Kloiber M, Piazza M, Riggio M, Rinn F, Widmann R, Yamaguchi N (2013) In situ assessment of structural timber using semi-destructive techniques. Mater Struct 47(5):767-785

Thomson WT, Dahleh MD (1998) Theory of vibration with applications, 5th edn. Prentice Hall, Upper Saddle River

Verkasalo E, Leban JM (2002) MOE and MOR in static bending of small clear 520 specimens of Scots pine, Norway spruce and European fir from Finland and France and their prediction for the comparison of wood quality. Paperi ja Puu/Paper and Timber 84(5):332-340

Wang X, Ross R, Mattson J, Erickson J, Forsman J, Geske E, Wehr M (2002) Nondestructive evaluation techniques for assessing modulus of elasticity and stiffness of small-diameter logs. Forest Prod J 52(2):79-85

Williamson GB, Wiemann MC (2010) Measuring wood specific gravity..correctly. Am J Bot 97(3):519-524

Woodhouse J (1998) Linear damping models for structural vibration. J Sound Vib 215(3):547-569

Yeh CT, Hartz BJ, Brown CB (1971) Damping sources in wood structures. J Sound Vib 19(4):411-419

Zabel RA, Morrell JJ (1992) Wood microbiology: decay and its prevention. Academic Press, San Diego 